\title{
Engaging and empowering business management students \\ to support the mitigation of climate change through sustainability auditing
}

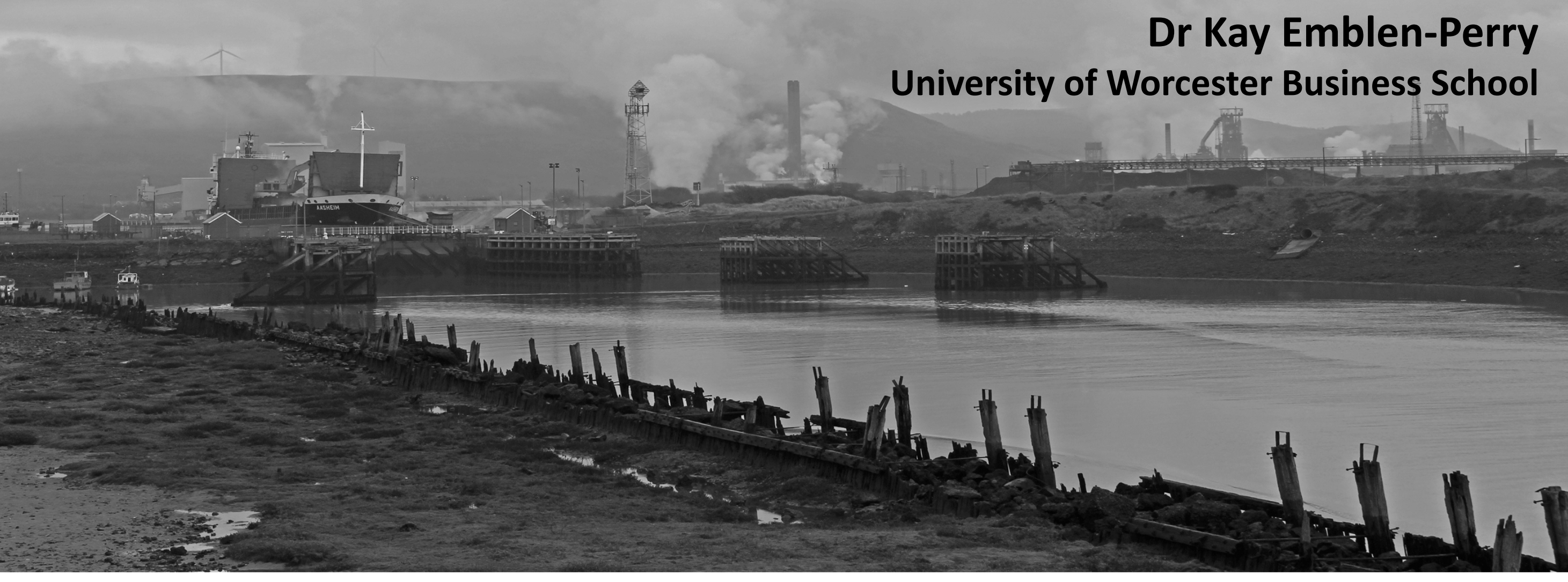


- Why engage business management students in the mitigation of climate change?

- Why use an audit as a teaching tool?

- My teaching practice

- The benefits students get from Audit-based Learning

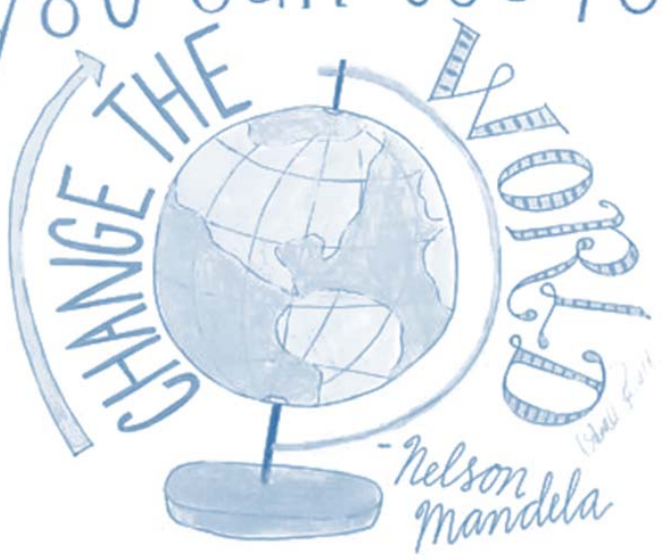


The learning environment is an important determinant of behaviour...

... so if we want to change behaviour we need to change the learning environment

\section{"I'm a business} student ...

\section{I don't do}

Climate Change"

Empowering business management students 
- Urgent need to enhance EfS for business management students to:

$\checkmark$ Improve knowledge of climate change mitigation, adaption and impact reduction

$\checkmark$ Empower future graduate employees to act as active prosustainability citizens

$\checkmark$ Empower future graduate employees to change businesses from within

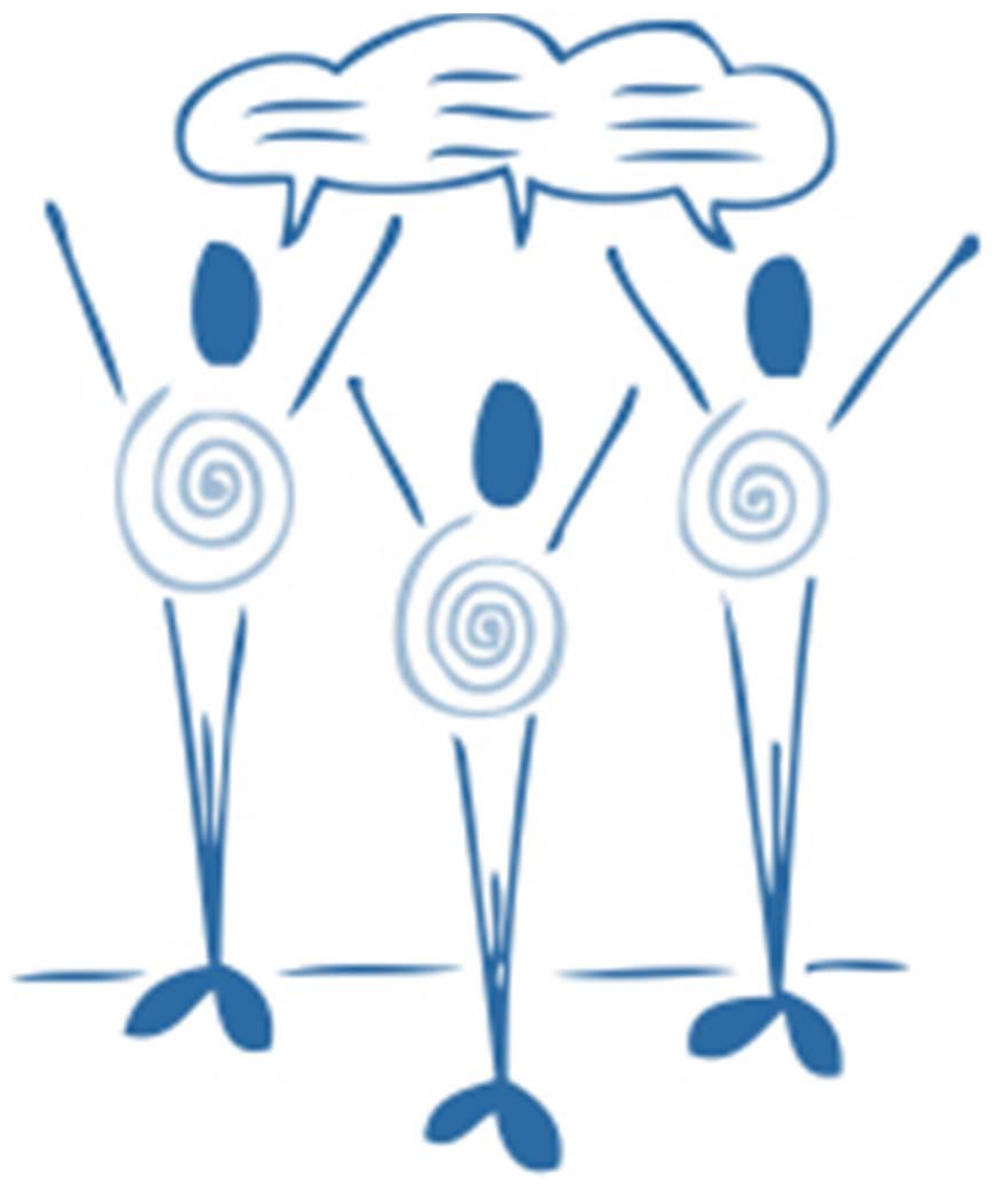

Empowering business management students 
- In response, I have designed an innovative pedagogy for 3 rd year business management undergraduates that focuses means and methods of teaching on the completion of a GRI Sustainability Audit of a fictional case study company

$\checkmark$ Replicates a real world business audit

$\checkmark$ The company audited is presented as online case study

- The sustainability audit is assessed

Empowering business management students

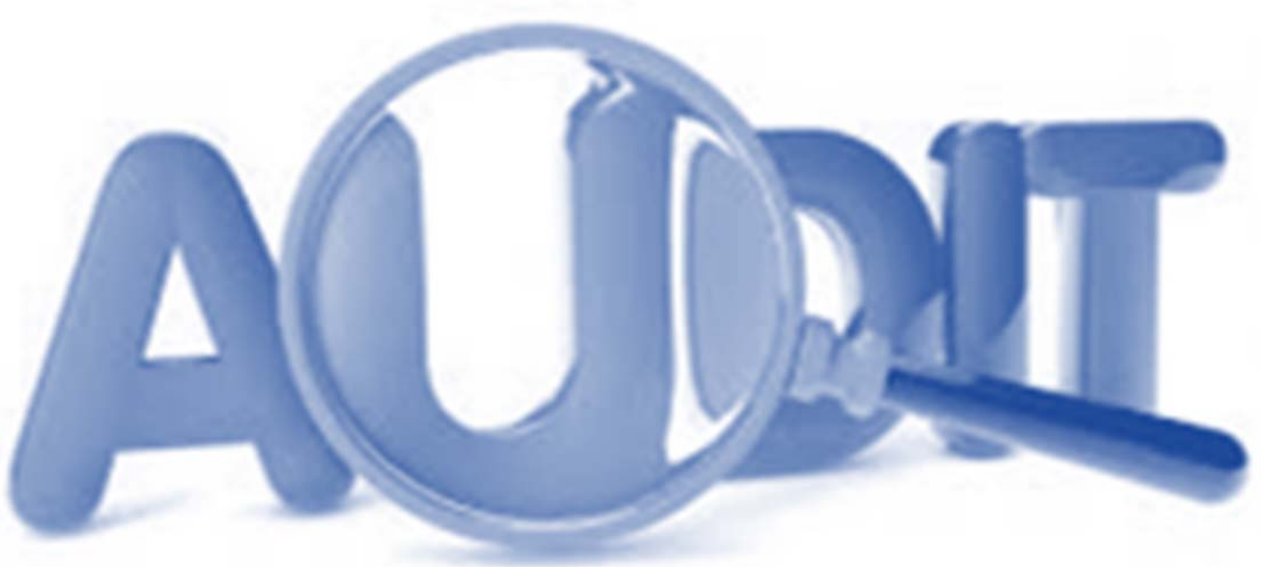


- A sustainability audit: "A methodical examination of a organisation's procedures and practices that determine/influence environmental, social or economic impacts"

- Audits are a long standing method of improving sustainability performance:

$\checkmark$ Management procedure that allows an organisation to detect problems before they affect operations (Hillary, 2004)

$\checkmark$ Create a benchmark from where to measure subsequent change (Clark and Whitelegg, 1998)

$\checkmark$ Enable the development of a systematic approach to improving sustainability performance whilst improving economic performance (Viegas et al., 2013)

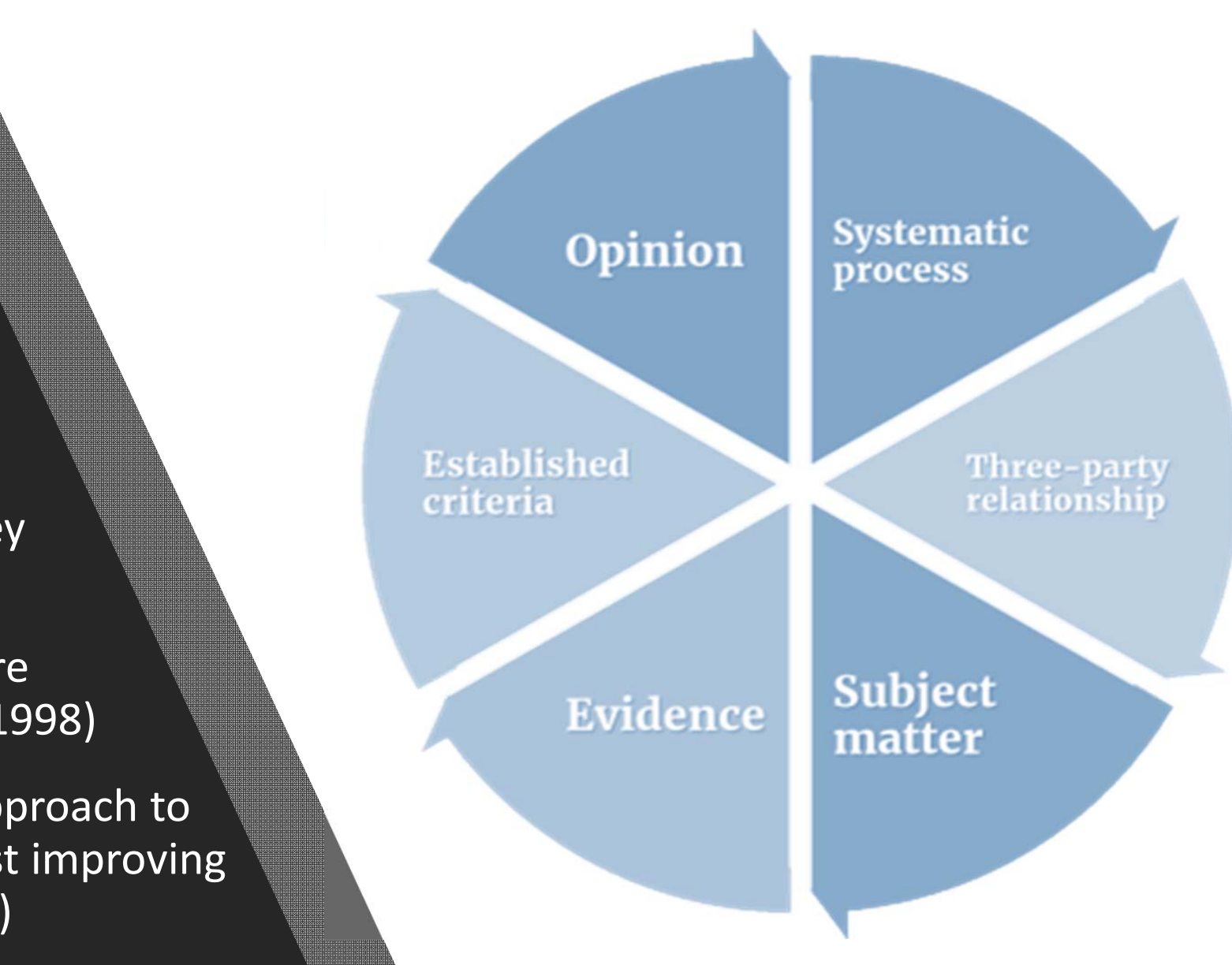

Rationale for sustainability audits in learning, teaching and assessment 
- An audit may be considered an effective tool to engage students in information management

$\checkmark$ Collecting

$\checkmark$ Collating

$\checkmark$ Synthesising

$\checkmark$ Evaluating

- These represent higher order cognitive skills which many graduates lack (Benn and Dunphy, 2009; Drayson, 2014; Edie, 2015; Laurinkari and Tarvainen, 2017)

Rationale for sustainability audits in learning, teaching and assessment




- An audit for learning and teaching and as an assessment engages students in:

$\checkmark$ Learning by doing

$\checkmark$ Project-based learning

$\checkmark$ Active learning in a real world setting

Pedagogic approach




Means and methods of teaching with a sustainability audit

Teaching in practice

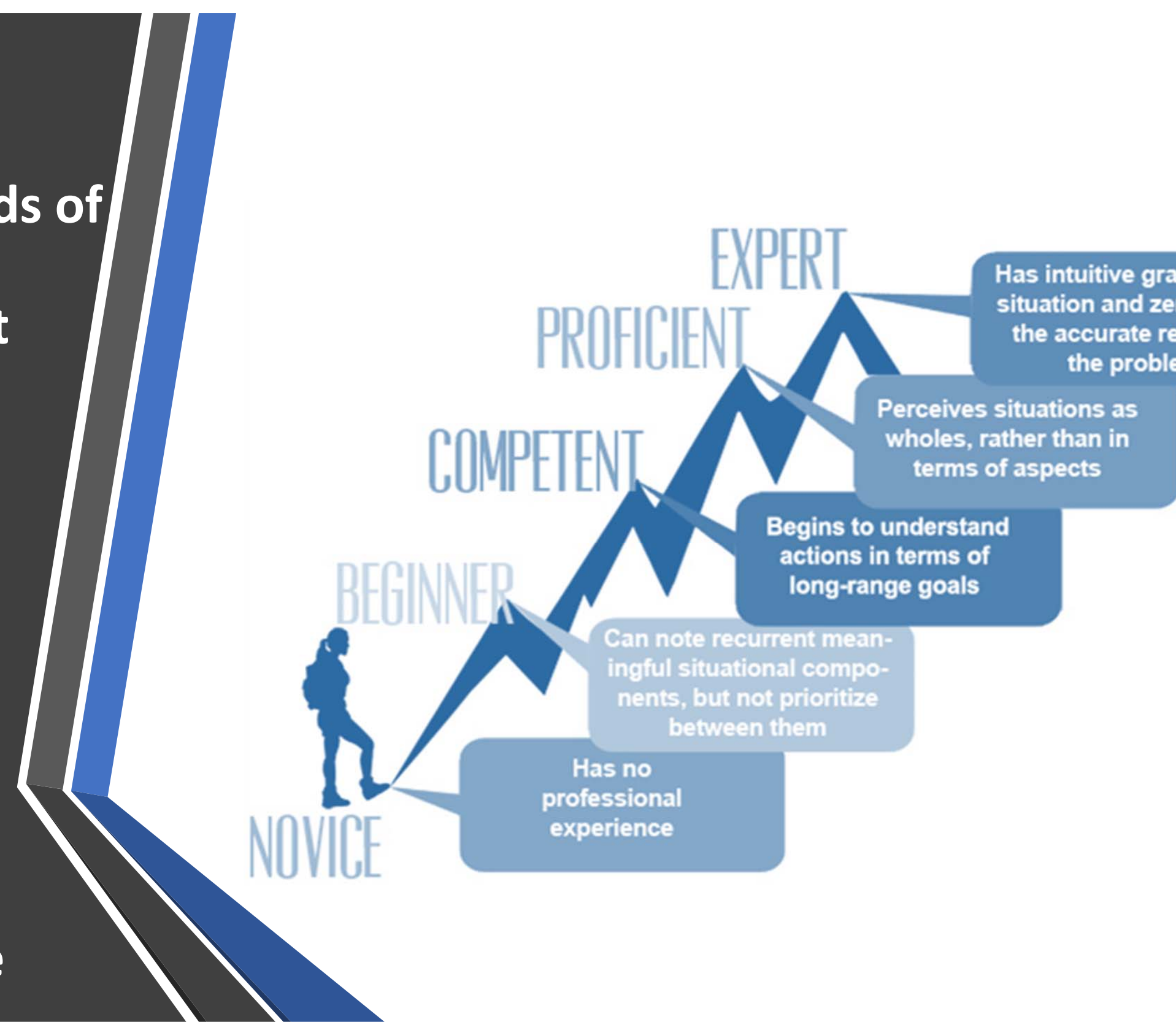


Students complete a modified GRI audit template...

Teaching in practice: The Audit

\begin{tabular}{|c|c|c|c|c|c|c|}
\hline $\begin{array}{l}\text { GRI } \\
\text { Ref }\end{array}$ & AUDIT TOPIC & $\begin{array}{l}\text { AUDIT } \\
\text { QUESTIONS }\end{array}$ & $\begin{array}{l}\text { AUDIT ANSWER } \\
\text { (Sustainability performance - } \\
\text { current situation observed } \\
\text { during audit including } \\
\text { historical actions impacting on } \\
\text { current sustainability) }\end{array}$ & $\begin{array}{l}\text { EVIDENCE } \\
\text { USED }\end{array}$ & $\begin{array}{l}\text { POST AUDIT } \\
\text { RECOMMEND- } \\
\text { ATION }\end{array}$ & $\begin{array}{l}\text { ACTION BY } \\
\text { AND } \\
\text { RECOMM- } \\
\text { ENDED } \\
\text { TIMING }\end{array}$ \\
\hline$\overline{\mathrm{E} 1}$ & $\begin{array}{l}\text { Energy consumption } \\
\text { by type and source }\end{array}$ & & & & & \\
\hline E2 & $\begin{array}{l}\text { Energy saved due to } \\
\text { conservation and } \\
\text { efficiency } \\
\text { improvements }\end{array}$ & & & & & \\
\hline
\end{tabular}


... of a fictional company presented as an online mixed media case study

... with photos

Teaching in practice: The Auditee

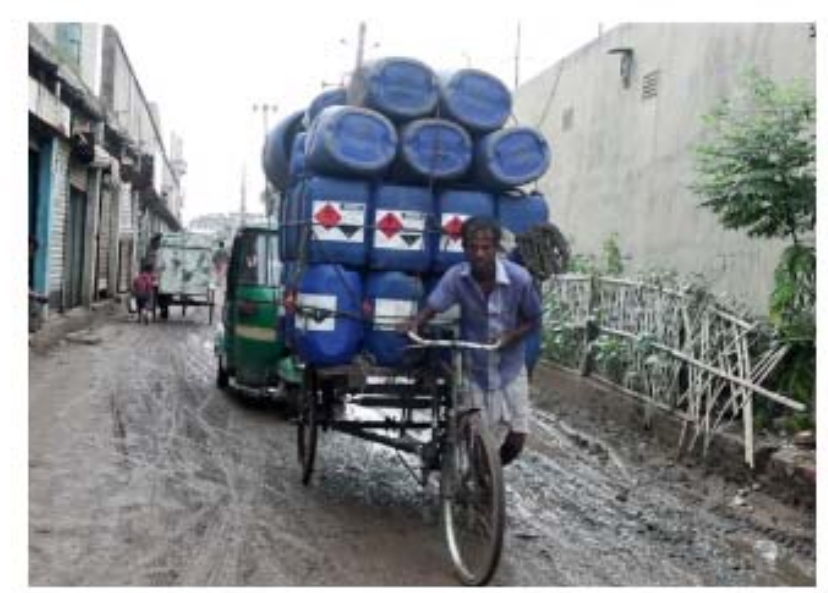

Photo 5: Workers moving solvents for use in production

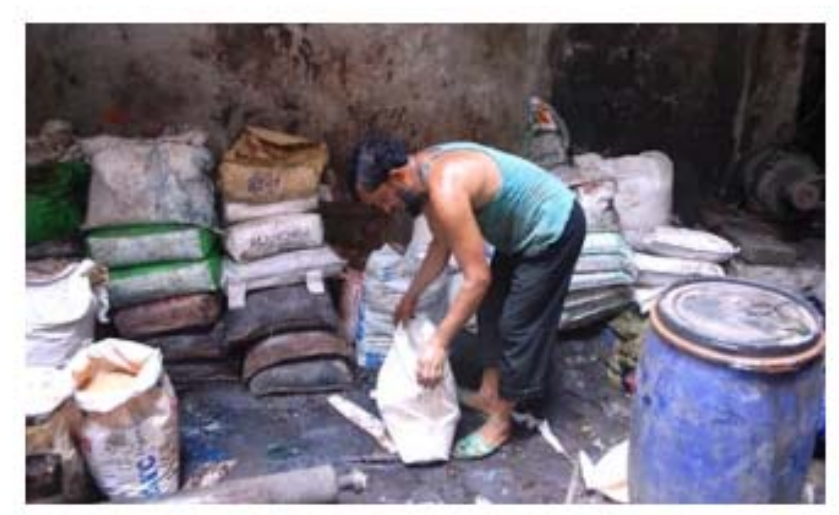

Photo 6: Workers moving raw materials for use in plastic production

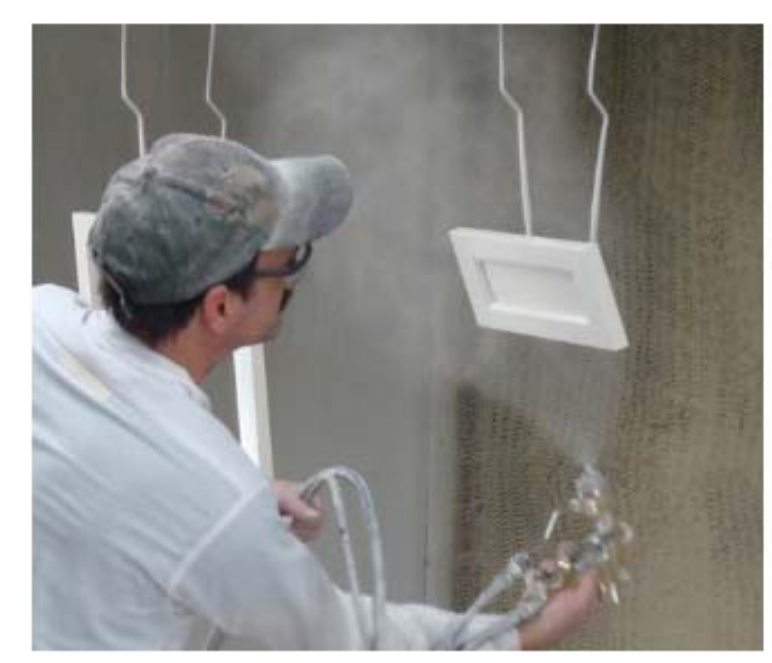

Photo 10: Spraying paint on plastic mouldings

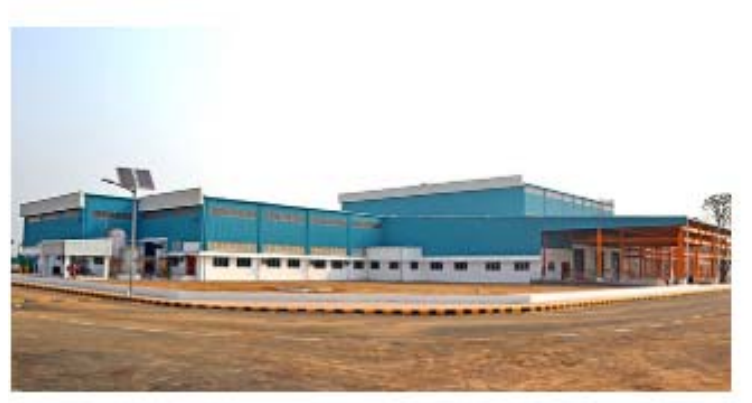

Photo 11: APEC Kolath factory 


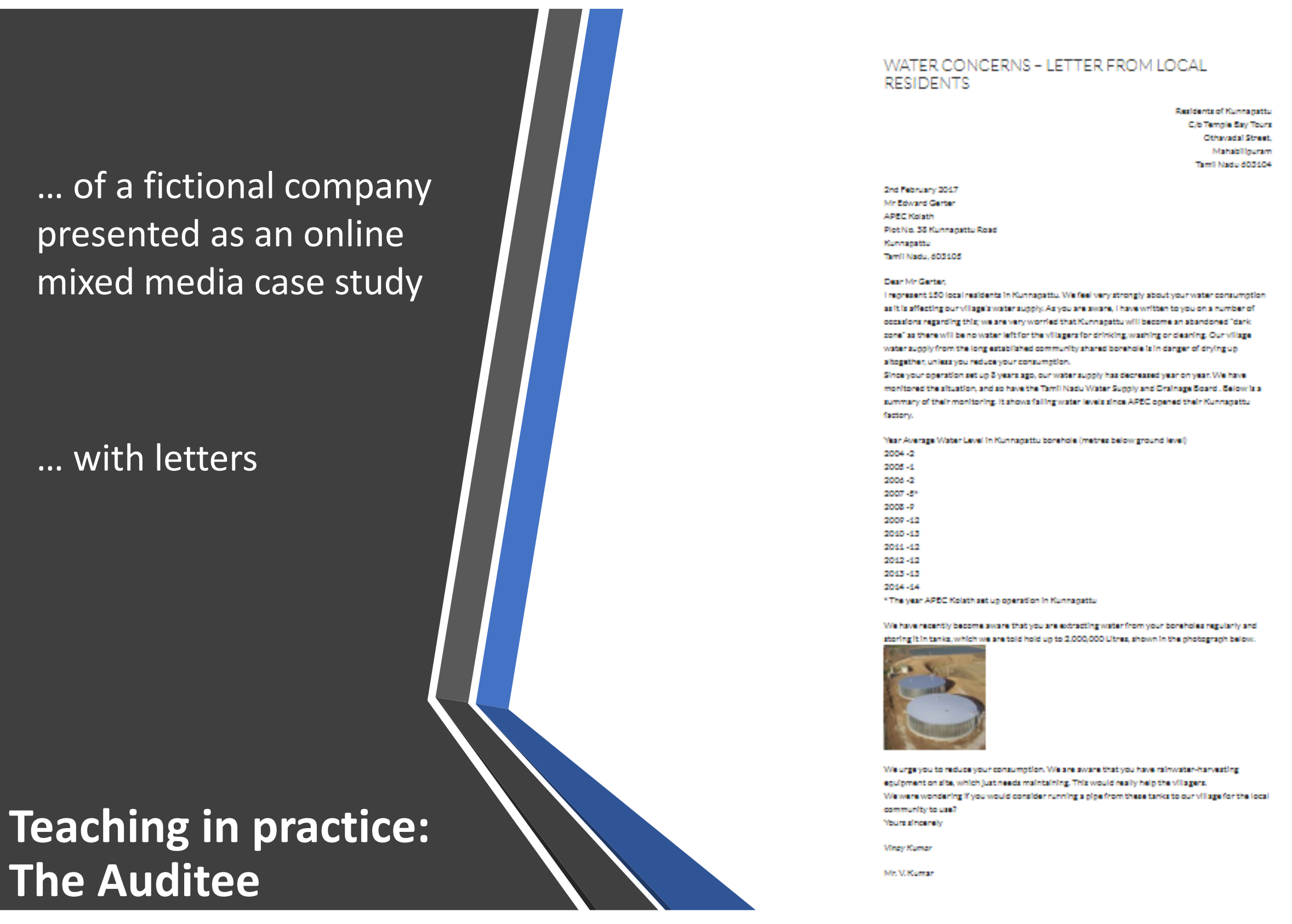


... of a fictional company presented as an online mixed media case study

... with resource consumption figures

Teaching in practice: The Auditee

\section{Electricity consumption figures 2017 and 2018}

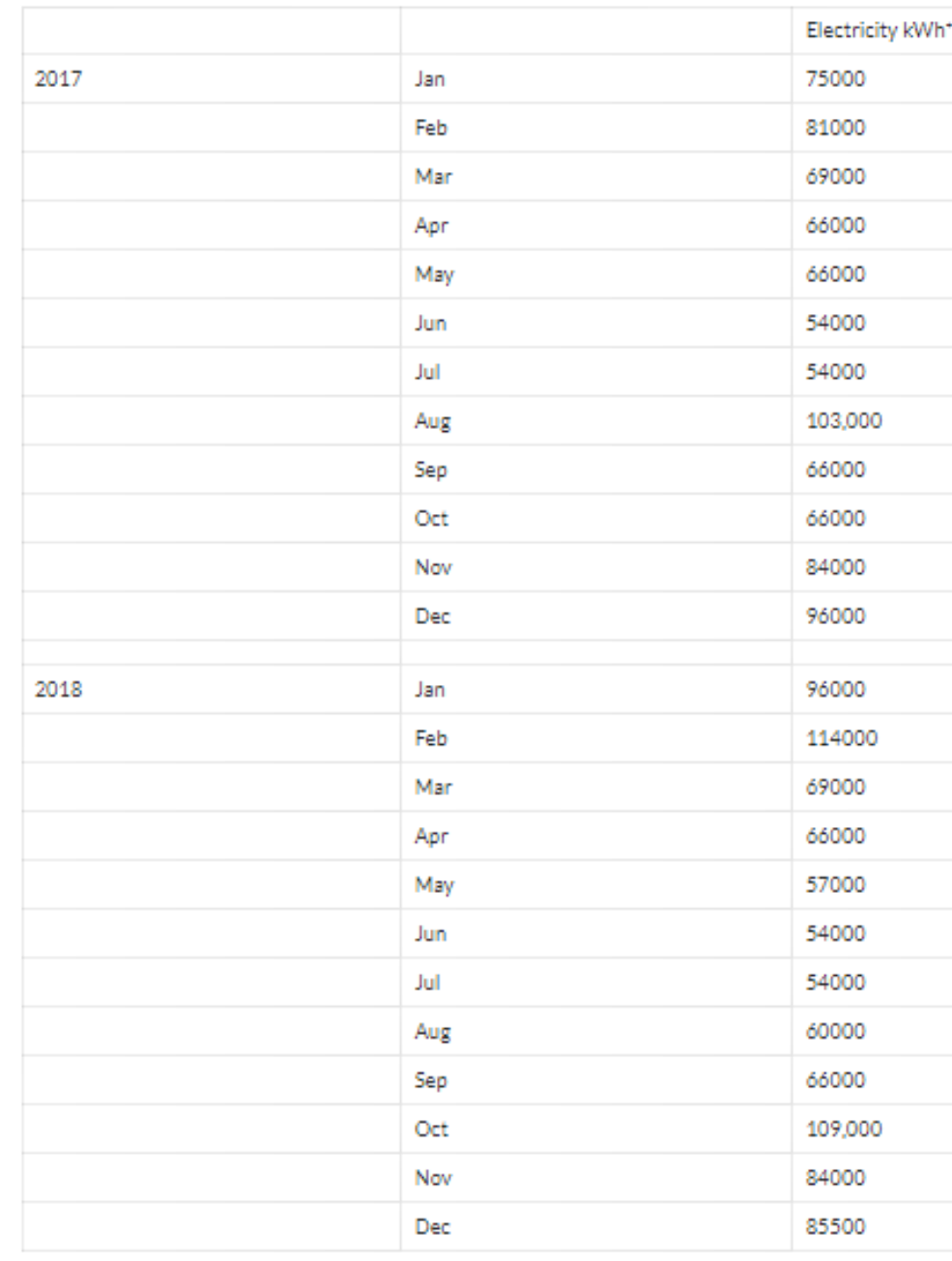

${ }^{1}$ The $\mathrm{kWh}$ is a unit of energy equivalent to one kilowatt ( $1 \mathrm{~kW}$ ) of power expended for one hour (1 h) of time. 
... of a fictional company presented as an online mixed media case study

... with employee information

Teaching in practice: The Auditee
Wage sheet

\begin{tabular}{|c|c|c|c|c|c|}
\hline surname & Gender & DOB & Position & $\begin{array}{c}\text { Wage } \\
\text { (Rupees) }\end{array}$ & Received wages \\
\hline Amarnath & M & 14-Jun-98 & Factory & 80 & amgarrath \\
\hline Ankola & M & 08-May-94 & Factory & 90 & Bs \\
\hline Badesh & M & 21-Jun-96 & Factory & 90 & $x$ \\
\hline Bahi & M & 11-Aug-92 & Factory & 90 & Bah \\
\hline Balakrishnan & M & 19-0et-99 & Factory & 80 & \\
\hline Behari & M & 03-Jul-88 & Factory & 90 & Behan: \\
\hline Bhatti & M & 29-Sep-98 & Factory & 80 & bhatti \\
\hline Boparai & M & 25-Jul-01 & Factory & 45 & $x$ \\
\hline Chakrabarti & M & 18-Jan-00 & Factory & 80 & $a c$ \\
\hline Chandna & M & 15-Jul-77 & Factory & 120 & Cha \\
\hline Chandrakala & M & 14-Sep-90 & Factory & 90 & $c$ \\
\hline Chatterjee & M & 28 -Jan-99 & Factory & 80 & Chatteñia \\
\hline Chatterjee & M & 17-Apr-97 & Factory & 80 & Jce \\
\hline Chatterji & M & $01-\mathrm{feb}-00$ & Factory. & 80 & $x$ \\
\hline Chatteril & F & 27-Apr-02 & Factory & 50 & he \\
\hline Chatterii & Im & 29-Dec-75 & Factory & 120 & Charterii \\
\hline Chatterii. & $F$ & 17-oct-79 & Factory & 120 & $m e$ \\
\hline Chiba & M & 02-Jul-85 & Factory & 120 & Clinber \\
\hline Dibyendu & $F$ & 14-Sep-93 & Factory & 65 & $x$ \\
\hline Duranjaya & M & 25-Aug-62 & Factory & 120 & $D D$ \\
\hline Ghandl & M & 16-Jul-98 & Factory & 80 & ag \\
\hline Girish & M & 28-Sep-97 & Factory & 80 & cusa \\
\hline Gokarju & M & 18-Apr-61 & Factory & 120 & $x$ \\
\hline Gordha & $F$ & $12-0 e c-78$ & Factory & 100 & Gordha \\
\hline Gurjala & M & 19-May-85 & Factory & Dismissed & - \\
\hline Gurinder. & M & $22-0 c t-86$ & Factory & 120 & $a_{a}$ \\
\hline llyas & M & $01-A p r-60$ & Factory & 120 & he \\
\hline Jahnavi & $F$ & 12-Jun-62 & Factory. & 100 & क \\
\hline Jaspreet & M & 19-Mar-63 & Factory & 120 & $x$ \\
\hline Kalirai & M & $12-\operatorname{Jan}-63$ & Factory & 120 & $\star$ \\
\hline Kaniktar & M & 08-Sep-90: & Factory & 90 & Caniktar \\
\hline Kasturirangan & M & 01-Mar-60 & Factory & 120 & \\
\hline Kayeeda & M & 30-Mar-02 & Factory & 48 & \\
\hline Khilnani & M & 18-Sep-82 & Factory & 120 & 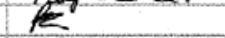 \\
\hline Koduri & M & 03-Jul-89 & Factory & 90 & $2 k$ \\
\hline Kondapalli & M & 01-Dec-98 & Factory & 80 & Kondapalli \\
\hline Koppolu & M & 28-Apr-79 & Factory & 120 & $x$ \\
\hline Koritala & $M$ & 18-0ct-78 & Factory & 120 & \\
\hline Kunwarjit & M & 14-Sep-68 & Factory & 120 & PK \\
\hline Lakhani & M & 12-May-76 & Factory & 120 & Laken... \\
\hline Lokhande & M & 23-Nov-93 & Factory & Dismissed & - \\
\hline Maddukuri & M & 19-Sep-74 & Factory & 120 & \\
\hline
\end{tabular}


... of a fictional company presented as an online mixed media case study

... with environmental impacts details

Teaching in practice: The Auditee
LETTER REPORTING LAGOON WATER SAMPLE FINDINGS

\section{Mr Nigel Simmons}

APEC Kolath

Plot No. 38 Kunnapattu Road

Kunnapattu

Tamil Nadu 6023105

India

\section{5th May 2018}

Dear Mr. Simmons,

On 14th May 2018 I sampled the water from the lagoon receiving discharged water from APEC Kolath. These samples were sent to the Tara Laboratory in New Delhi for analysis.

I have now received the laboratory reports from the analysis and can confirm the presence of high levels of dioxins and phthalates water samples. These are all above the legal limits imposed by the Ministry of Water Resources in the Water (Prevention and Control of Pollution) Act, 1974. The contaminants are detailed below:

Summary of Analysis of Lagoon Water Sample Identification

Measured Concentrations of Indicator Parameters in lagoon water (mg/l) not shown in this summary

Sample summary

Polycholrinates dibenzo-P-dioxins ( $\mathrm{PCDD} / \mathrm{Fs}$ )

Hydrogen chloride

Sulphate

Dissolved Carbon Dioxide

Sulphuric Acid

Chlorine

Phosphoric Acid

If I can be of any help with water decontamination or further water or soil sampling please do not hesitate to call.

Yours sincerely,

S. Rajan

Prof. Sanwar Jat Rajan

Environmental Consultant, Tara Enviro 


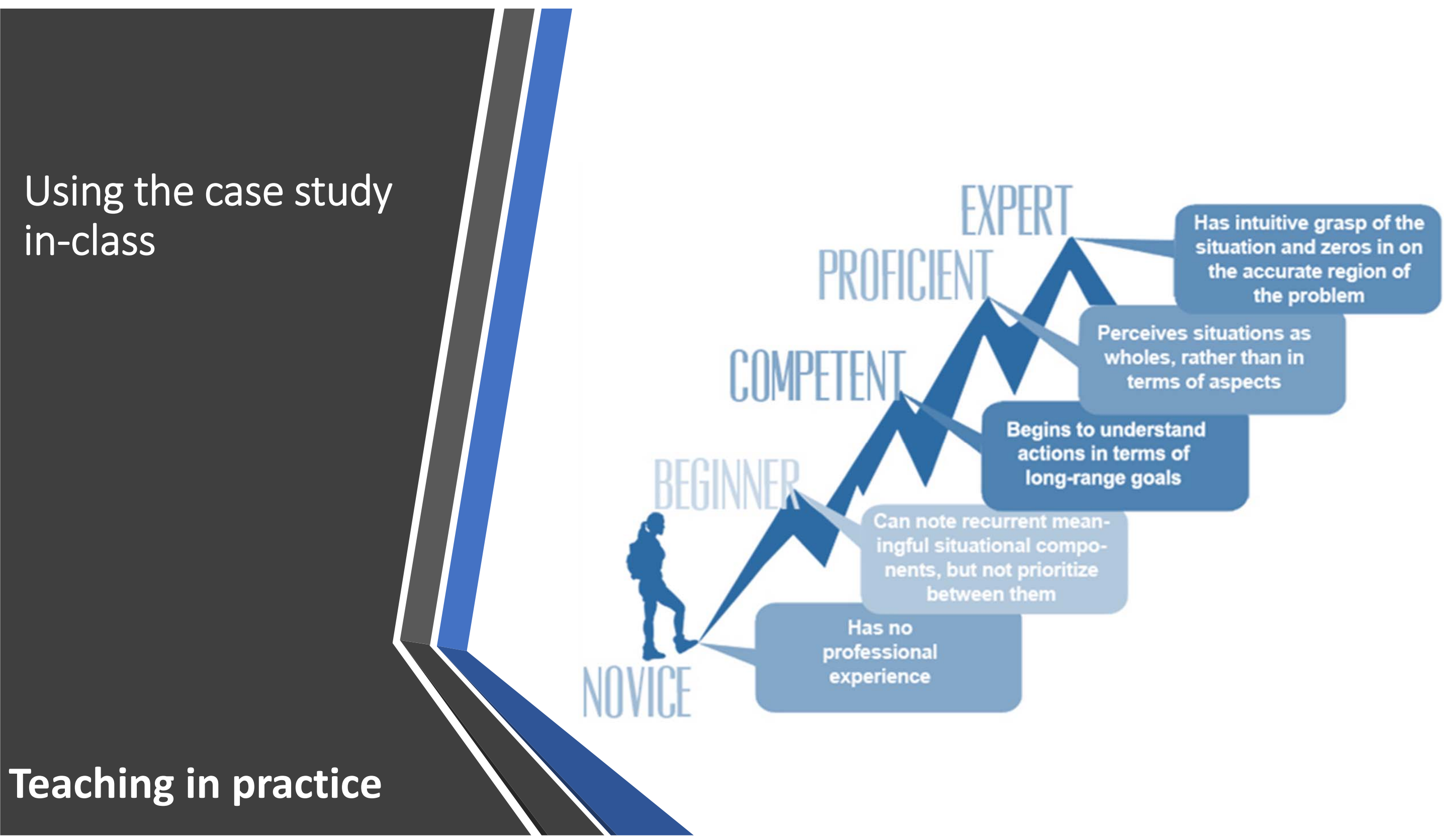


Theory is linked to the assignment

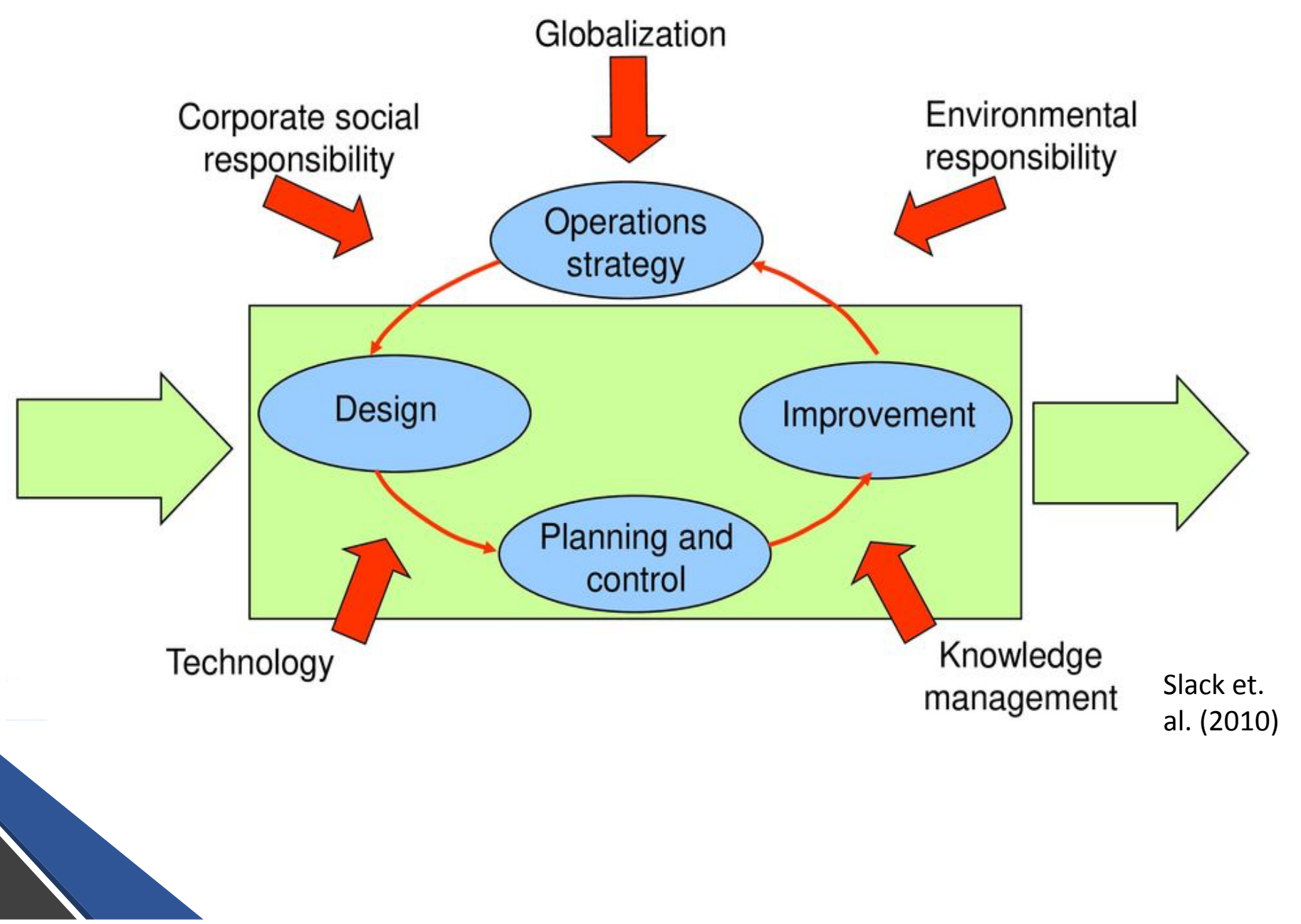

Applying theory to the case study: Operational sustainability modelling

\section{Teaching in practice:} In-class activities 
Theory is linked to the assignment

Applying theory to the case study: Supply chain modelling

Teaching in practice: In-class activities

A SIPOC is a high-level view of a process. It stands for Suppliers, Inputs, Process, Outputs, and Customers:

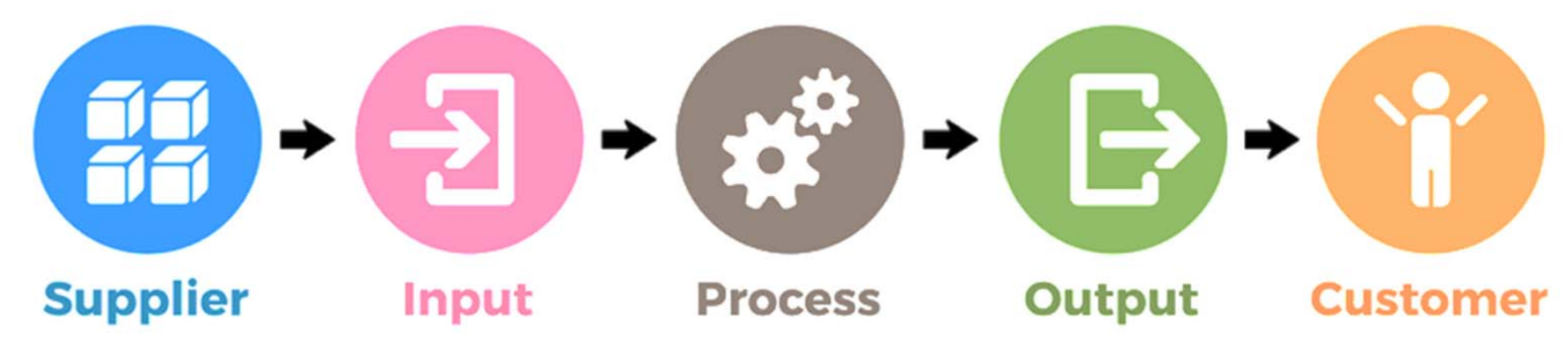

Person/Organization Resource that is Series of steps where Resource that is that provides Input added to a Process an Input converts to the result of a

Person/Organization that receives to a Process. by a Supplier. an Output. Process. products or services. 
All in-class activities are linked to the audit
Applying business practice to the case study: Site plan mapping

Teaching in practice: In-class activities

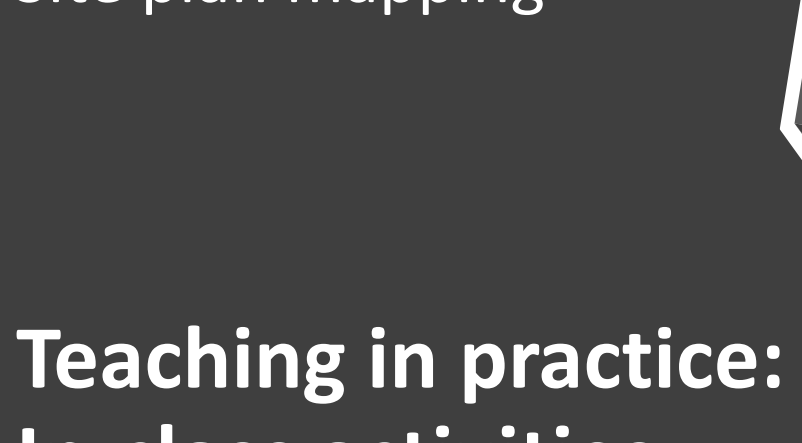

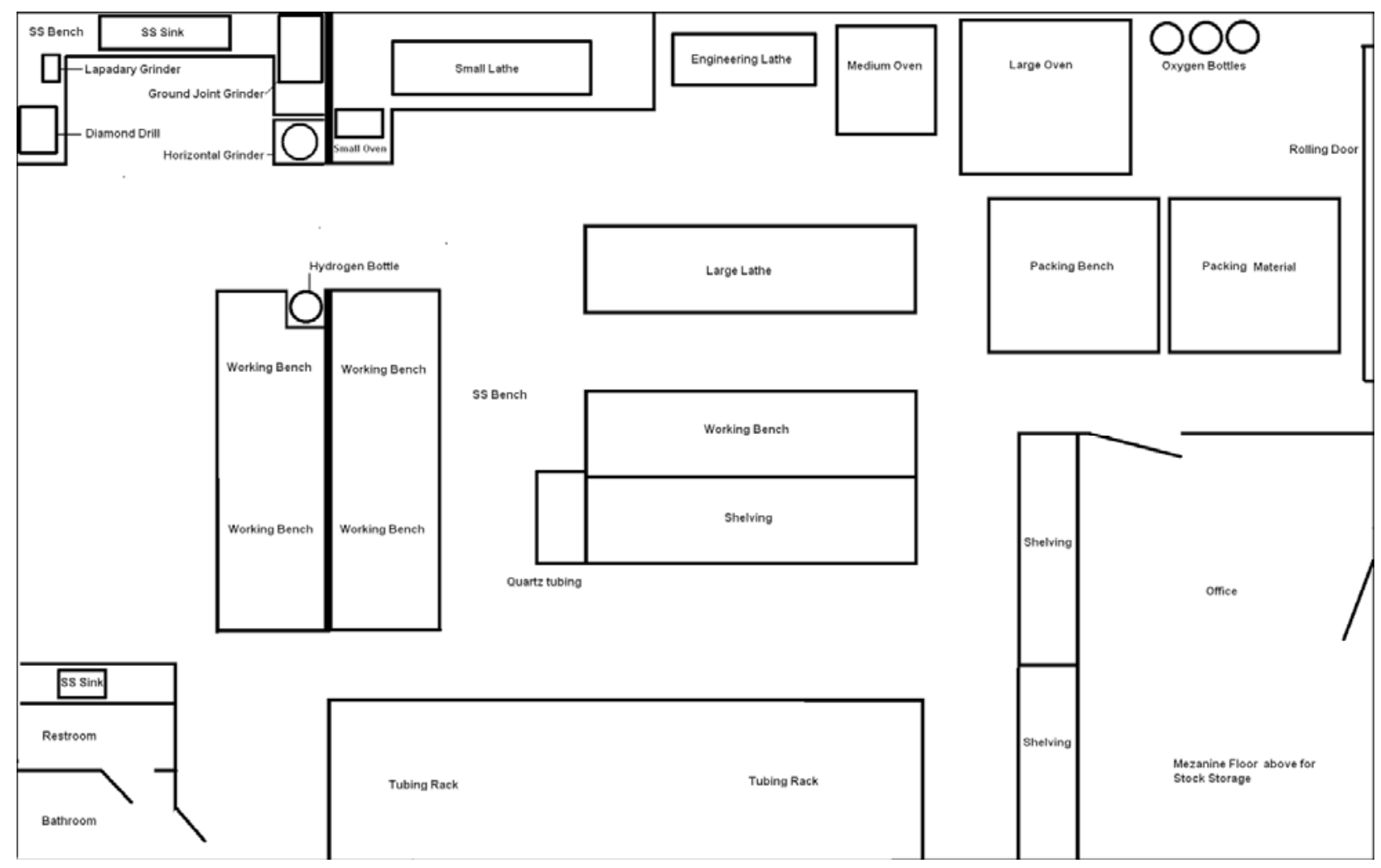




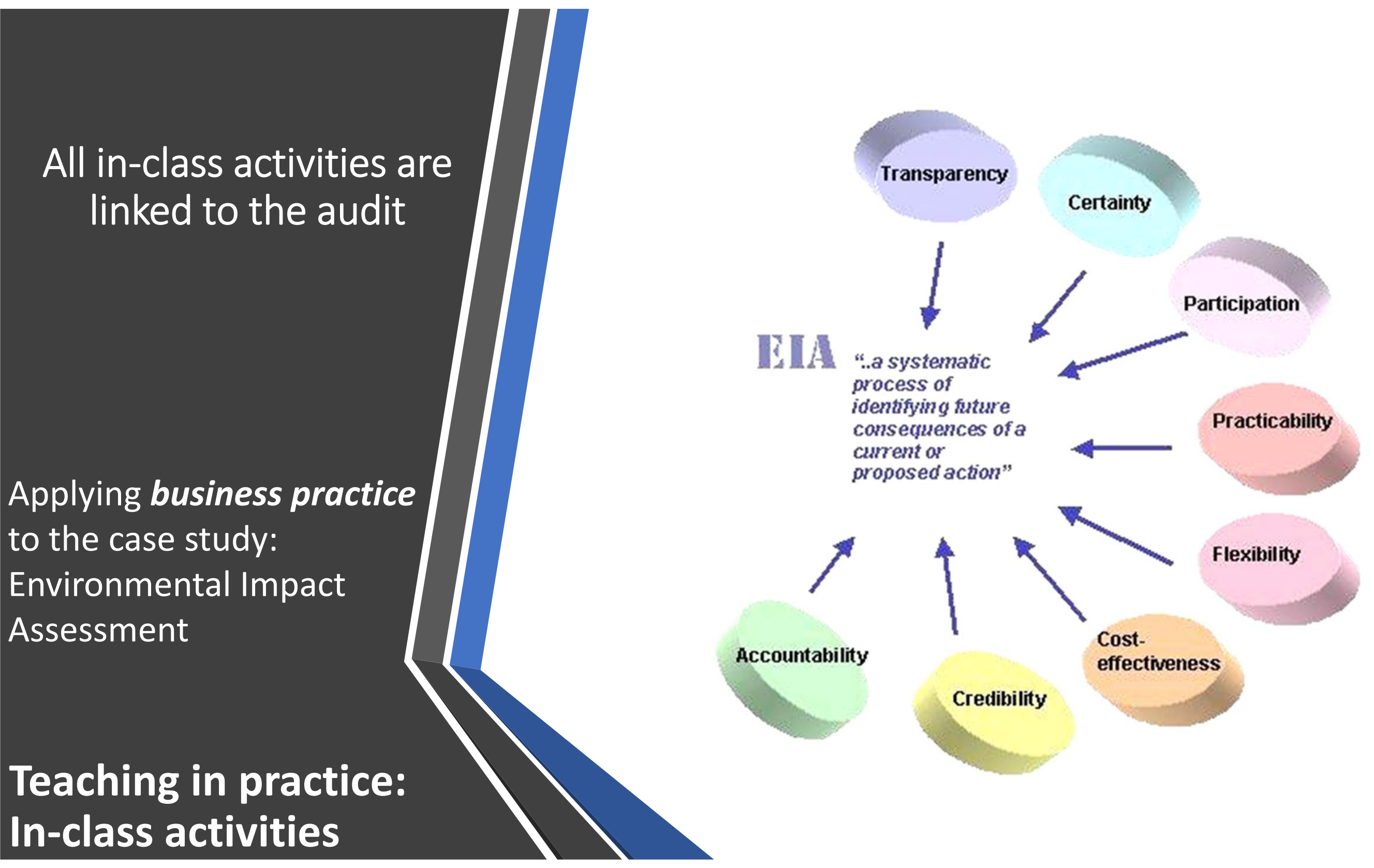




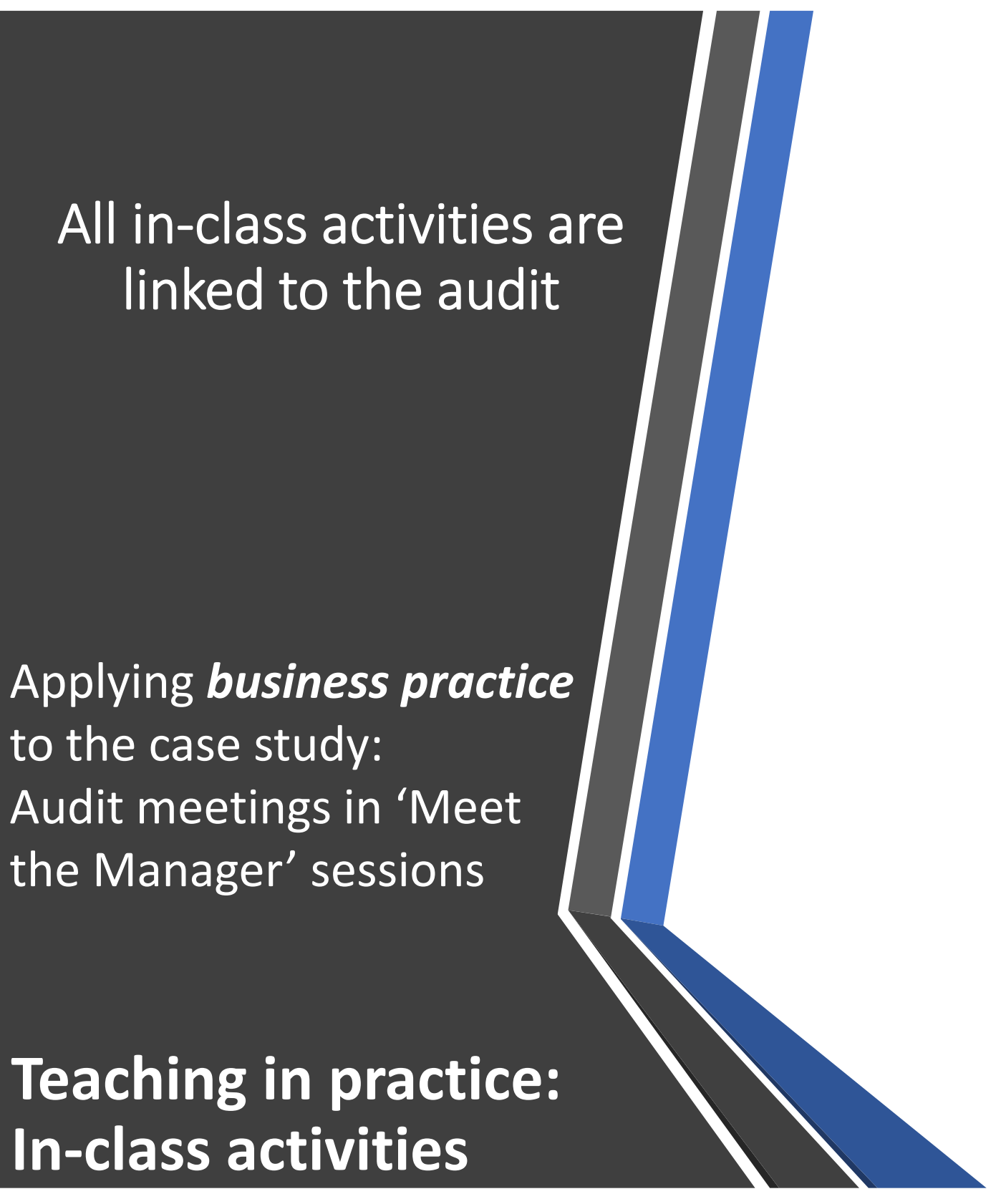




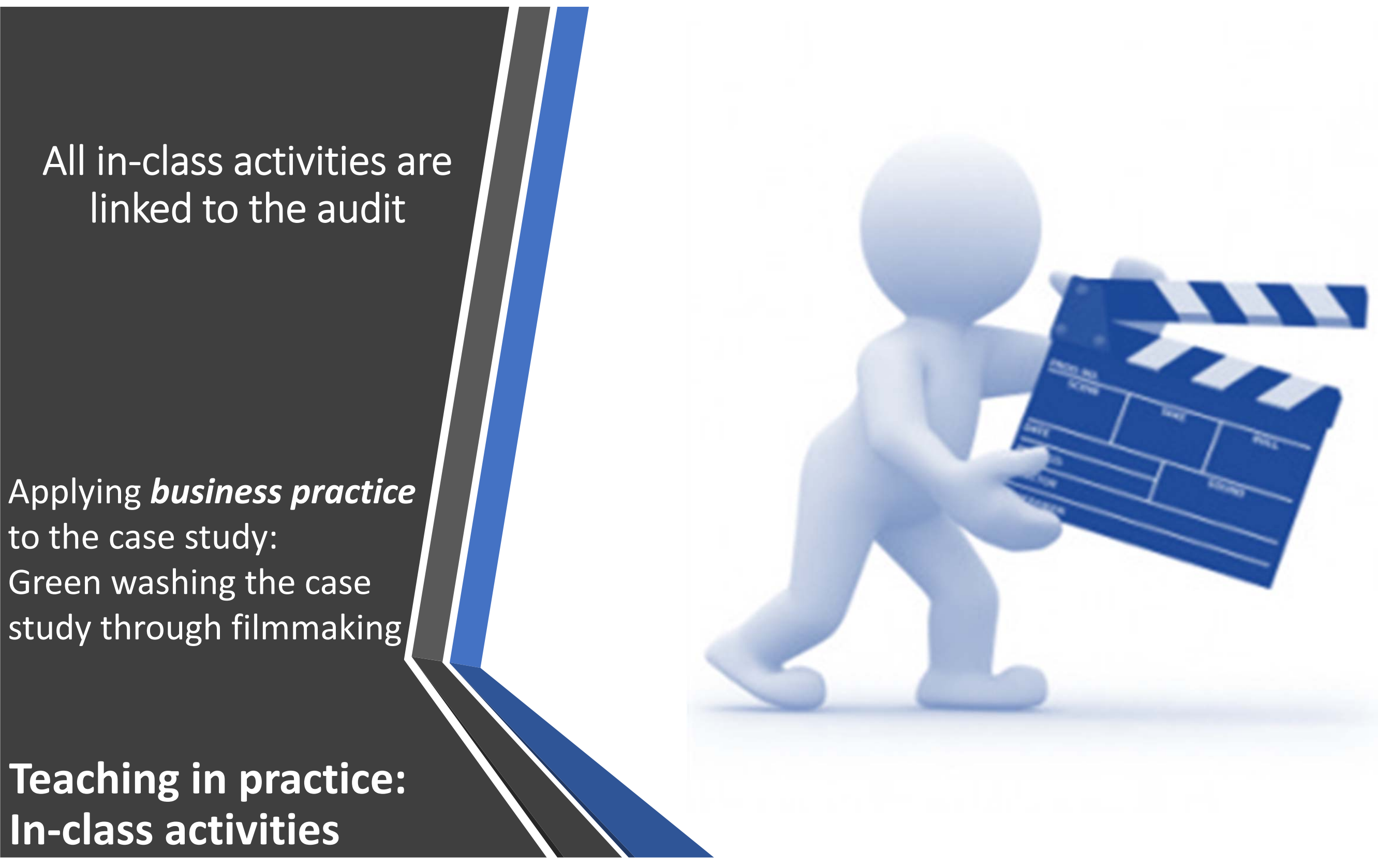



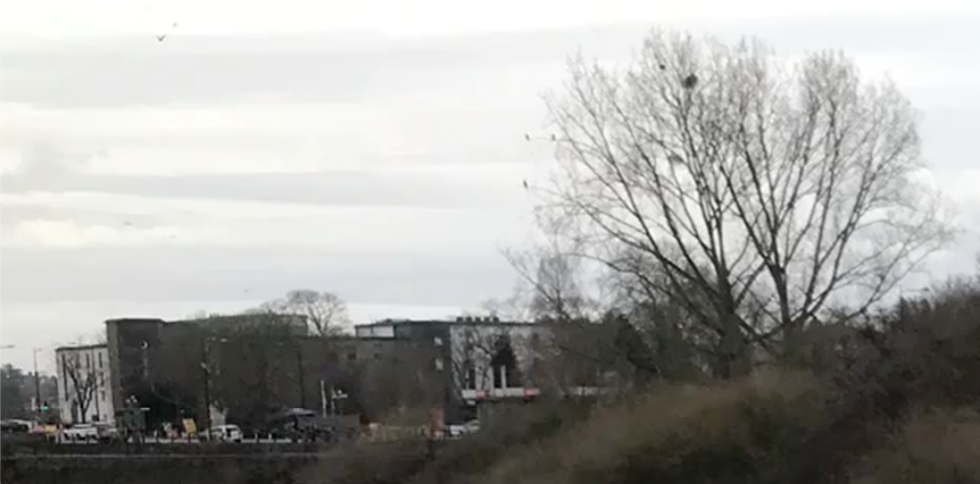

NH. W W Ham Nof

7

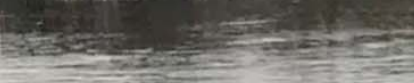

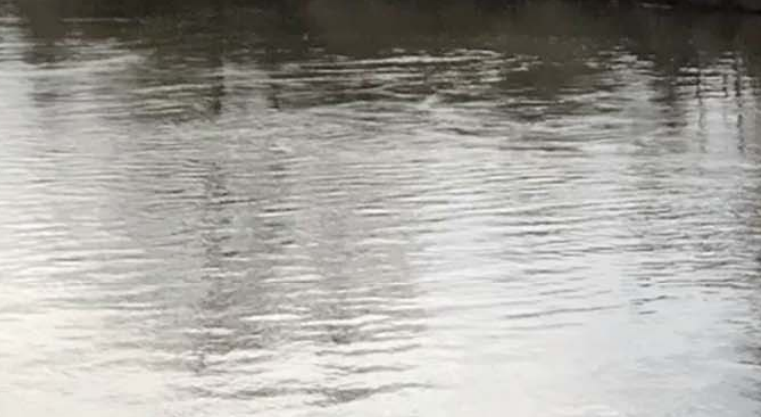


- Using an audit as a pedagogic tool can provide:

$\checkmark$ Interactive, experiential learning

$\checkmark$ Active, real-world learning

$\checkmark$ Challenges to individuals' thinking and behaviours

$\checkmark$ Engagement of future sustainability professionals

- Audit-based Learning supports development of graduates with:

$\checkmark$ Knowledge skills and values needed to promote climate change mitigation

$\checkmark$ Employment skills for successful careers

$\checkmark$ Tools to feed forward into future (or current) workplace

\section{Conclusions}

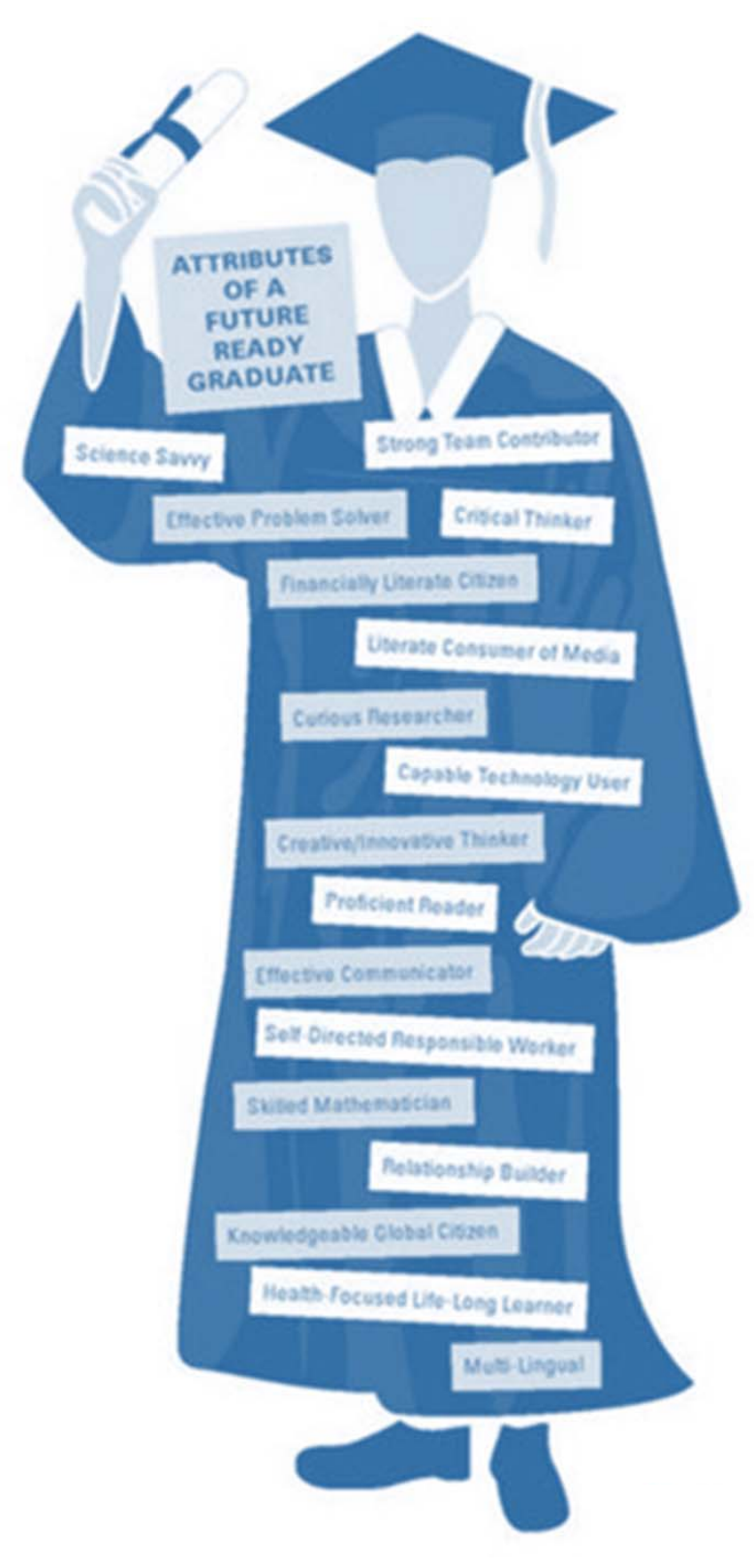






